\title{
Theoretical stress and strain distribution across thick - walled filament wound composite.
}

\begin{abstract}
Monolithic thick cylinder theory with linear elastic orthotropic laminate properties was employed successfully to predict the inside and outside surface strains. While applying the theory to thick-walled tubes it is necessary to consider the different states of stress and strain on the inside and outside surfaces and to consider the effect of radial stress. Threedimensional stress analysis was used throughout and is presented for general interest in a form suitable for computer application. Numerical example was used to compare the results obtained from the equations with the results obtained with use of CompositePro software and good agreement was achieved between them both.
\end{abstract}

Keyword: Orthotropic laminate; Thick-walled filament wound composite tubes; Threedimensional stress and strain analysis. 